\title{
VARIOUS ASPECTS OF THE EXPLOITATION OF MA- RINE CURRENT ENERGY WITH TIDAL TURBINES
}

\author{
Aurel - Dan Maimon \\ University "Dunarea de Jos" of Galati, \\ Faculty of Naval Architecture, Galati, \\ Domneasca Street, No. 47, 800008, Romania, \\ E-mail:dan.maimon@ugal.ro
}

\begin{abstract}
The main purpose of this paper is to present a short review of the actual progress on the tidal energy and on the tidal energy convertors: turbines, dam systems, oscillating wings and their operation characteristics. The energy of the oceans: the tides, the waves, the difference of osmotic pressure between the fresh water and that of the oceans, the thermal gradient in the depths of the oceans, the sea currents, represents a huge reservoir of electricity estimated at an annual production of $120.000 \mathrm{TWh}$. The energy of the tides could provide a lot of electricity, but a power station of this type causes damage to the environment of the estuary where it is built and to its wild life because it prevents the passage of fish. Tidal turbines could be an alternative solution in environment protection..
\end{abstract}

Keywords: tidal energy, tidal turbines, oscillating wings

\section{INTRODUCTION}

All movement is energy. Tides, ocean waves and rivers flowing around the world contain kinetic and potential energy that can be used to run turbines and generate electricity, reducing our dependence on fossil fuels. One can even take advantage of the differences in salinity (salt content) and temperature that characterize water bodies to create dynamic forces capable of producing electricity.

These different forms of renewable marine energy are available as long as tides continue to rise and fall, and rivers and streams continue to flow.

Tidal energy is obtained by the movement of the tides which is formed under the influence of the gravity of the Sun and the Moon. It can take two forms: the tidal current and the tidal range.

A major European Commission study assessing current tidal energy resources for
106 locations across Europe, with predefined features making them suitable for tidal energy exploitation, estimated an exploitable resource from these sites of $48 \mathrm{TWh}$ per year (European Commission). The total capacity of this site selection is an installed capacity of over 12,000 MW marine current turbines.

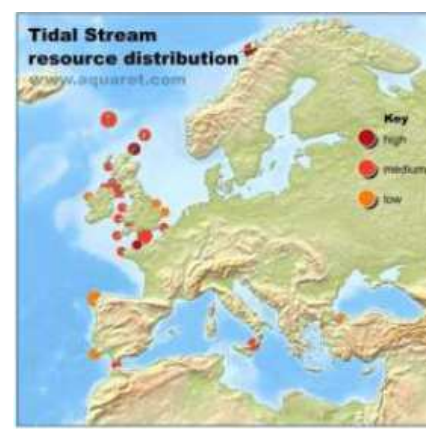

Fig.1. Resource distribution of tidal currents

A more recent Black \& Veatch (Black $\&$ Veatch for Carbon Trust) study suggests a UK extractable resource estimated at 22 TWh for a tidal stream, using a modified and 
more accurate methodology. Other countries with exceptionally high resources are Ireland, Italy, the Philippines and Japan. Figure 1 shows the average tidal range for 237 locations along European coastal lines. These locations are between 50 and $100 \mathrm{~km}$ offshore and the distance from one location to another is of approximately $100 \mathrm{~km}$.

\section{CHARACTERISTICS OF TIDES AND OTHER MARINE CURRENTS}

The use of tidal energy is old, as evidenced by the many tide mills. The recovery can be done in its potential forms: sea level variation and exploitation via a dam, or kinetics: direct exploitation of currents by turbines placed directly in the flow, like submarine wind turbines, also called tidal turbines. These two principles thus give rise to two families of tidal systems. One of the advantages of the tides is their high predictability, which facilitates planning and makes it possible to better integrate such production systems into networks, even if there is no correlation between availability and demand. With dam systems, the storage effect in upstream and downstream basins can be used to make storage, possibly by pumping in the advantageous parts of the cycle.

Depending on the location, there are different types of tides. The most energetic have about 2 cycles per day with a period of about 12.5 hours and an amplitude that varies substantially, sinusoidally, on a cycle. Tidal ranges or amplitudes (between high and low levels) can vary considerably depending on the location and the tidal coefficient (20 to 120). The tidal coefficient is a factor to be applied to determine the tidal range with respect to a site-specific reference value. For example, the reference tidal range of the Mont Saint Michel is $11 \mathrm{~m}$, the highest coefficient is reached at the equinoxes and leads to a maximum tidal range of $13 \mathrm{~m}$. This French region is one of the first sites in the world, with the highest known tidal range being reached in Fundy Bay in Canada with a value of $16 \mathrm{~m}$. Figure 2 shows changes in the tidal coefficient, during a year, on a site.

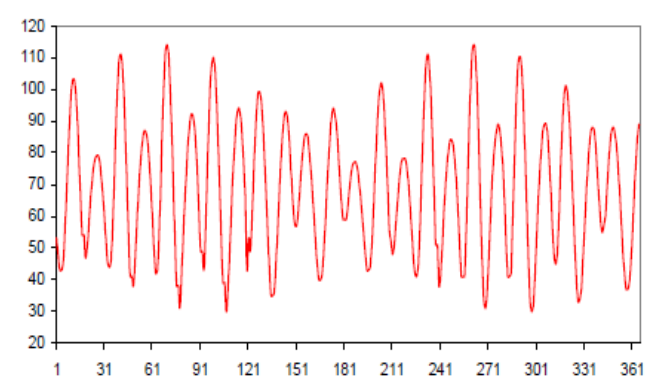

Fig.2. Examples of the tidal coefficient variation over a year

Tidal currents are more intense when the depth is low and their intensity is maximum at the surface to reach a zero value at the bottom by effect of "boundary layer". The evolution of the velocity $\mathrm{v}$ as a function of the distance $\mathrm{z}$, counted from the surface, is of the type:

$$
v=v_{0} \cdot\left[\frac{x}{H}\right]^{\alpha}
$$

where v0 is the velocity at the surface and $H$ is the depth (typical value of $\alpha: 1 / 7$ ).

Tidal phenomena are not the only ones causing marine currents. The rotation of the earth, temperature differences, density gradients (salinity function) create continuous currents, such as the Gulf Stream, whose average annual velocities (there are indeed seasonal variations), in certain places and regions, are high enough to indicate a possible commercial exploitation. This is particularly the case off the coast of Florida where we observe currents reaching speeds of 2 $\mathrm{m} / \mathrm{s}$. The tidal currents could thus be described as alternating currents and the others as continuous currents. We only insist that continuous currents play a decisive role in the climate and that they already seem to be affected by global warming, so we cannot consider their exploitation on a large scale without taking into account the ecological consequences it could have. 


\subsection{Tidal production systems with dam}

The construction of dams modifies the configuration of the coastal site concerned as well as the ecosystem and requires heavy investments. For these reasons, there has been very little achievement in the world and the largest, by far, is the Rance tidal power plant. Commissioned in 1966, it produces approximately $0.540 \mathrm{TWh}$ annually, or more than $90 \%$ of the world's tidal power. Its 24 groups of $10 \mathrm{MW}$ are integrated in a dam, which also serves as a road to connect Saint Malo to Dinard (see figure 3). There have been few such large power projects (greater than $1 \mathrm{MW}$ ) except in Canada and China with $20 \mathrm{MW}$ and $5 \mathrm{MW}$, respectively. Other projects in progress are that of Fundy Bay in Canada, where a $5300 \mathrm{MW}$ is planned, and that of Severn in England with 216 turbines with a total capacity of 8640 MW. In total, $87 \mathrm{GW}$ have been pre-feasibility studies worldwide for an annual productivity of 190 TWh. One exception, however, is that the Sihwa Dam (12.7 km long) built in the early 1990s in South Korea for reasons other than energy, and which has an area of $173 \mathrm{~km}^{2}$, that must be equipped with a tidal power plant of $250 \mathrm{MW}$ which would then be the most powerful in the world.

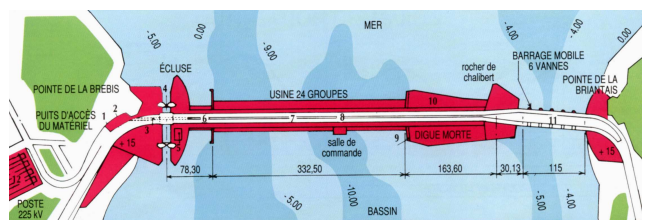

Fig.3. Diagram of the tidal power plant at La Rance (240 MW)

The operation of a tidal power plant is similar to that of run-of-the-river plants because the drop height remains low, but, unlike the latter, there is a choice: that of operating in single or double effect. In the single-action cycle, the dike valves are open during the rising tide and fill a pond. When the sea level is sufficiently down so that the drop height is sufficient, valves are opened so that the water returning to the sea drives a turbine. This is the principle implemented in the old tide mills. Remember that hydraulic power is expressed by:

$$
P_{M}=\rho \cdot g \cdot h \cdot Q \quad(W)
$$

where $\rho$ is the density of the water, $h$ is the height of fall and $Q$ is the flow in $\mathrm{m} 3 / \mathrm{s}$. Knowing that the height of the fall varies as the basin empties and the sea level rises (approximately sinusoidally), it is clear that a strategy to optimize the opening times of the valves must be implemented to make the most of the resource.

The double-action cycle makes it possible to exploit the available power both at the rise and at the descent of the tides. Reversible turbines (operating in both directions of current) are then required. Such groups are used for the Rance power station. Optimal exploitation is quite complex. For example, it may be interesting to pump water when the tide goes down to increase the ground level and later to tilt it with an advantageous head.

At low and medium tides, only one simple effect cycle is used:

- during the rising tide, all the valves are open and the estuary fills with a slight shift, due to the transit time of the water, following the level of the sea;

- once the high tide is reached, the gates are closed and the groups work in pumping to raise the level of the water in the estuary (for example by $2 \mathrm{~m}$ ), which, in this particular cycle, exceeds the maximum sea level ;

- during the descent, when the sea level reaches about its average value, the groups are engaged in turbining and the production is made with a good elevation until the sea is raised to the vicinity of its average level. The energy spent during the pumping is thus restored with a factor of almost two thanks to the increase of the height of fall.

With strong tides (coefficients higher than 105 , about $20 \%$ of the tides with Saint Malo), it is the cycle double effect which is put to advantage:

- during the rising tide and even a little beyond, the water is turbined and produces electricity; 
- then the groups are stopped, the valves are opened to accelerate the filling of the basin until the level of the sea reaches its average value;

- finally, we return to the operation of the single-action cycle where the water accumulates in the basin until the sea returns to its average level.

In the double-acting cycle, the water level in the basin varies almost sinusoidally with a phase shift of a quarter of a period compared to that of the sea and its maximum value remains lower than that at sea. Today, the experience gained has made it possible to automate operation and make the most of the installation.

The hydraulic units of the Rance plant are of the horizontal axis bulb type, they are composed of Kaplan turbines (diameter 5.35 m) with 4 blades and variable pitch, each coupled directly to a synchronous machine, which is itself electrically coupled to the network without electronic converter (fixed speed of $93.75 \mathrm{rpm}, 32$ pairs of poles). In the Sihwa plant, the technology will be roughly the same with 10 groups of $25.4 \mathrm{MW}$, an annual productivity of $0.55 \mathrm{TWh}$, or 2100 hours equivalent to full power $(2250 \mathrm{~h}$ for the plant of the Rance).

\subsection{Artificial lagoons}

One way to overcome topographic constraints may be to create an artificial lagoon and thus an offshore tidal power plant. That's what Tidal Electric Ltd. offers. Feasibility studies have been carried out, such as that of Swansea Bay in the United Kingdom where there is an area of $5 \mathrm{~km}^{2}$ in which the depth of the seafloor at low tide is between 1 and 5 $\mathrm{m}$, which makes possible the construction of a circular dike. The average accessible power is proportional to the square of the tidal range and the basin area. Thus, in Swansea Bay, with a lagoon of $5 \mathrm{~km}^{2}$ and tidal ranges up to $7 \mathrm{~m}$, we can expect a power of $60 \mathrm{MW}$ and an annual energy of about $0.187 \mathrm{TWh}$ with bidirectional groups exploiting the doubleacting cycle previously described for the
Rance plant. But this technology must prove itself, especially as regards the resistance of the dike.

\subsection{Marine currents energy recovery sys- tems}

The free currents recovery technique is very close to that of the wind turbines, except that the direction of the currents is constant, that their direction is alternative (effects of tide) or continuous and that the turbines are in salt water (this technology has already been tested in freshwater, especially in the Amazonian rivers). We thus find two large families of turbines, depending on whether the axis of rotation is vertical or horizontal, but also other more original technologies such as the one using oscillating flat wings functioning in the image of the tail of the marine mammals, or floating systems of the "impeller" type.

Apart from the Gulf Stream's energy extraction projects with huge power: 400 turbines of $15 \mathrm{MW}$ or 4000 turbines of $2.5 \mathrm{MW}$, most of the projects current issues concern tidal currents. We will focus our attention on technologies adapted to alternating tidal currents, knowing that they are mostly adapted to DC currents. The mechanical power, and the electric power (because the yields of the generators are close to $100 \%$ ), of a free-flow turbine is expressed by:

$$
P=\frac{1}{2} \cdot C_{p} \cdot v^{3} \cdot 5 \quad(W)
$$

where $\mathrm{Cp}$ is the hydrodynamic power coefficient, limited by the 59\% Betz law, $\rho$ the density of the water, $v$ the velocity of the current $(\mathrm{m} / \mathrm{s})$ and $\mathrm{S}$ the surface swept by the turbine. When the speed of currents varies sinusoidally, the power of the resource varies as the cube of this speed. Even if the speed fluctuations are not comparable to those of the wind, it can be interesting to level off the power beyond a nominal speed. This speed is an important parameter of a technicoeconomic optimization determined according to the characteristics of each site. Off the coast of Brittany, currents have maximum 
speeds of 0.5 to $3 \mathrm{~m} / \mathrm{s}$, at Raz Blanchard (La Hague peak) they reach $5 \mathrm{~m} / \mathrm{s}$, and in some Norwegian fjords speeds are measured for peaks of $7.8 \mathrm{~m} / \mathrm{s}$. With a minimum hydrodynamic efficiency $\left(\mathrm{C}_{\mathrm{p}}\right)$ of $30 \%$ (pessimistic: the values in the water are between 0.35 and 0.5 ), for 3 and $7 \mathrm{~m} / \mathrm{s}$ the power per unit of turbine area is respectively 4 and $50 \mathrm{~kW} / \mathrm{m}^{2}$. The characteristics of the turbines are exactly the same as those of wind turbines or those used in oscillating column houlogenerators. Figure 4 highlights the interest of varying the speed of rotation to maximize power recovery when the speed of the current changes according to the tide cycle. This same figure shows the electric power characteristic obtained by a variable pitch turbine and variable speed electric generator assembly. The variable speed makes it possible to fully exploit the possibilities of the turbine below the nominal speed (here $2.4 \mathrm{~m} / \mathrm{s}$ ) and the variable pitch makes it possible to level off the power beyond this value.
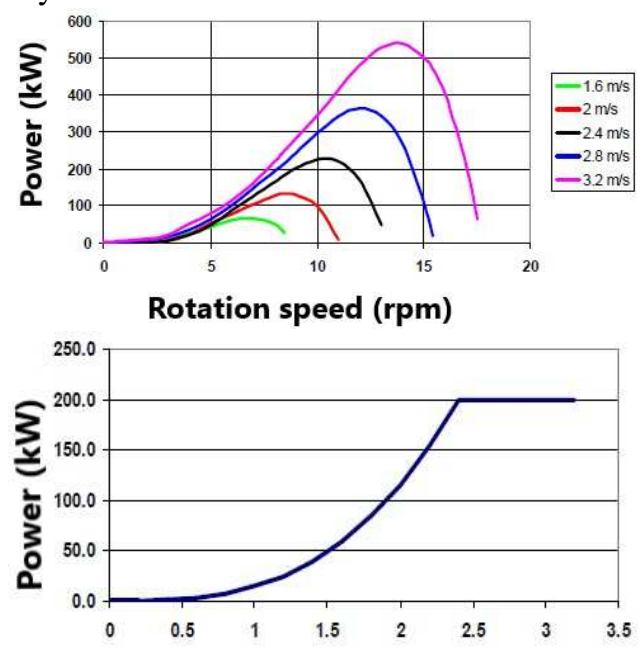

Current speed $(\mathrm{m} / \mathrm{s})$

Fig.4. Network of power characteristics of a tidal turbine according to the speed of rotation and the speed of the current. Typical power curve of a tidal turbine including power levelling off

The existence of an optimum nominal speed of the current (from which the power is leveled off) was highlighted in order to minimize the design cost of a tidal turbine. Although the kinetic power increases substantially with the cube of the speed of the current, it is advantageous to level off the power of the turbine to the strong currents (beyond a so-called nominal speed), which makes it possible to optimize the dimensioning of the current complete system considering that high velocity currents have a low occurrence. Figure 5 shows the effect of the "nominal" speed of the current above whose power is leveled off on the annual energy productivity. The study shows an economic optimum around a speed of $2.2 \mathrm{~m} / \mathrm{s}$, a value for which the energy produced would thus have the lowest cost price.
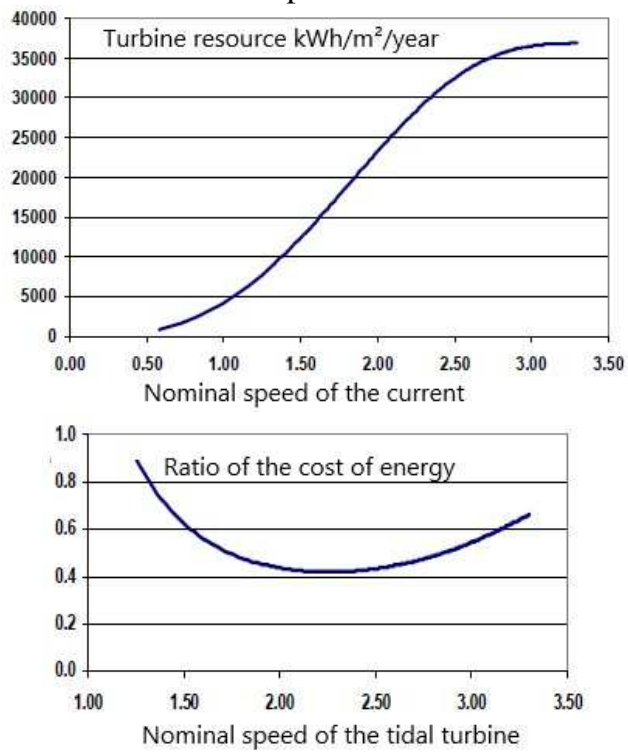

Fig.5. Influence of Design Nominal Speed (Current) on Annual Energy Productivity and Investment Cost to Production (called the "Energy Cost Ratio")

There are four categories of marine hydrogenerators:

- horizontal axis turbine

- vertical axis turbine

- swinging or oscillating wings

- floating wheel 


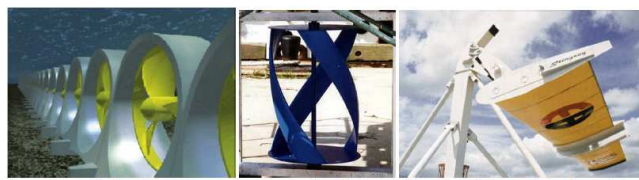

Fig.6. Types of marine hydrogenerators.

From left to right: horizontal axis turbine (HydroHelix), vertical axis turbine (Gorlov) and oscillating wing (Stingray).

Most of the imagined systems are completely submerged, except for HydroGen, which uses paddle wheels that float on the surface. The small power submersible generators can be floating, placed under a barge, which makes it possible to settle more easily the problem of the variations of heights due to the tides themselves and to make sure that the machines always remain in the vicinity of the surface. They can also be floating buoys and moored, as proposed by the company SMD Hydrovision or Ponte de Archimede with its KOBOLD turbine with vertical axis. This principle is already exploited in rivers. Hydrogenerators can also be placed on the bottom gravity base (Lunar Energy and HydroHelix) or carried by a metal monopile like those of Seaflow. In fact, the choice of bearing structures is mainly dictated by the depth and nature of the funds. Figure 7 shows, in a simplified way, the various media technologies. The monopoy is reserved for depths between 20 and $40 \mathrm{~m}$. It is driven into the ground (sand) by threshing. Offered in the offshore oil and gas industry, jacket structures, made of welded tubes that provide a wide surface hold, provide access to higher depths and / or rocky soil. These are also the technologies used or envisaged in offshore wind farms.

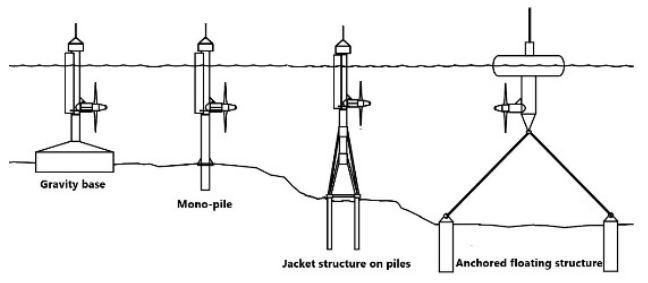

Fig.7. Different technological solutions for supporting hydrogenerators
The different prototypes or systems at the pre-industrial stage have powers of a few tens to a few hundred $\mathrm{kW}$. The tidal turbines of Marine Current Turbines Ltd (MCT), which have been the subject of much advanced work (Seaflow project), are analyzed more precisely. The Seaflow project consisted in installing in the Bristol Channel (20 to $30 \mathrm{~m}$ deep) a two-bladed turbine (composite blades) of $11 \mathrm{~m}$ diameter, with a variable pitch up to $180^{\circ}$ on a 42 steel pile, $5 \mathrm{~m}$ long and $2.1 \mathrm{~m}$ in diameter (mass 80 tons). The nacelle can move along the pile, fact which facilitates maintenance. The maximum power of $300 \mathrm{~kW}$ is reached at equinox tides. The turbine drives a variable-speed $450 \mathrm{kVA}$ cage generator (690 V and 3 pairs of poles) through a geared mechanical multiplier (ratio $1: 70)$. As in the case of wind turbines, the two-bladed rotors are less efficient than the three-bladed ones and induce more force pulsations but allow a lower mechanical simplification and cost, at least in this phase of development. Tests conducted have revealed significant power fluctuations (30 to $50 \mathrm{~kW}$ ) due to the blades passing in front of the pile (approximately every 2 seconds). Eventually, MCT provides monopiles supporting two two-bladed hydrogenerators of $500 \mathrm{~kW}$ each arranged on each side of the pile and whose flows will no longer be disturbed by the passage of the blades in front of the pile.

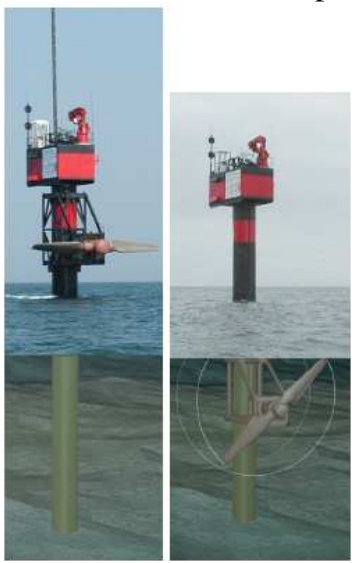

Fig.8. MCT Seaflow Hydrogenator photos (in maintenance and service) 
Figure 8 shows two photographs of the MCT Seaflow system with the emerged (for maintenance) and submerged (in operation) platform.

An estimate of the production potential has been made in the area between the English Alderney Island and the Pointe de la Hague (strong currents). The diameter of the turbines has been defined so that the lowest point is at a distance from the bottom equal to $25 \%$ of the depth and the highest point at $7 \mathrm{~m}$ below the surface (value taking into account hollows of swell $4 \mathrm{~m}$ and $3 \mathrm{~m}$ uncertainty). The complete hypotheses are defined with dual rotor machines (MCT type) of power 12, 24 and $38 \mathrm{MW}$ (diameters of 14, 20 and $25 \mathrm{~m}$ respectively), a cumulative installed capacity of $3243 \mathrm{MW}$, annual energy yield reaches 7.4 TWh, giving an equivalent annual duration at full power of $2280 \mathrm{~h}$.

The diversity of vertical axis machines is significant. These machines do not need to be oriented relative to the current and can quite easily associate matrix. They have a low "Tip speed ratio" ( $\lambda=\mathrm{R} . \Omega / \mathrm{v})$, therefore the optimal rotation speeds are low. Three categories of turbines are presented: Darrieus (of which the Kobold are part), Gorlov (see figure 6) and those from the LEGI whose blade tips have a break to reduce turbulence and improve hydrodynamic efficiency. Here, there is also presented the Enermar project of the Italian company Ponte di Archimede, experienced since 2002 in the Strait of Messina (between Sicily and Italy) where currents reach 1.5 to $2 \mathrm{~m} / \mathrm{s}$ with a depth of $20 \mathrm{~m}$. The Kobold turbine is suspended from a floating platform, $10 \mathrm{~m}$ in diameter, anchored $150 \mathrm{~m}$ from the shore. The turbine is 3 blades carbon fiber $5 \mathrm{~m}$ long (height) and $40 \mathrm{~cm}$ of chorde and the diameter is $6 \mathrm{~m}$. It drives, via a multiplier (ratio 90:1), a synchronous generator three-phase 4-pole (1500 rpm). The maximum power $(130 \mathrm{~kW})$ is provided with a current of $3 \mathrm{~m} / \mathrm{s}$ and a speed of rotation of $18 \mathrm{rpm}$. The tests, however, were performed with a current of $1.6 \mathrm{~m} / \mathrm{s}$ and the power was of only $16 \mathrm{~kW}$.
"Hydrofoil" winged oscillating systems are the last family of marine hydrogenerators, with the Stingray device as the most successful representative. The leading edges of one or more hydrofoil wings with parallel planes are arranged facing the current. The angle of attack of the wings is adjusted so that their lift is maximum and remains in the same direction as the movement. Hydraulic cylinders dampen the movement by compressing oil in a high pressure tank, the oil is turbined in a hydraulic motor that drives a variable speed electric generator.

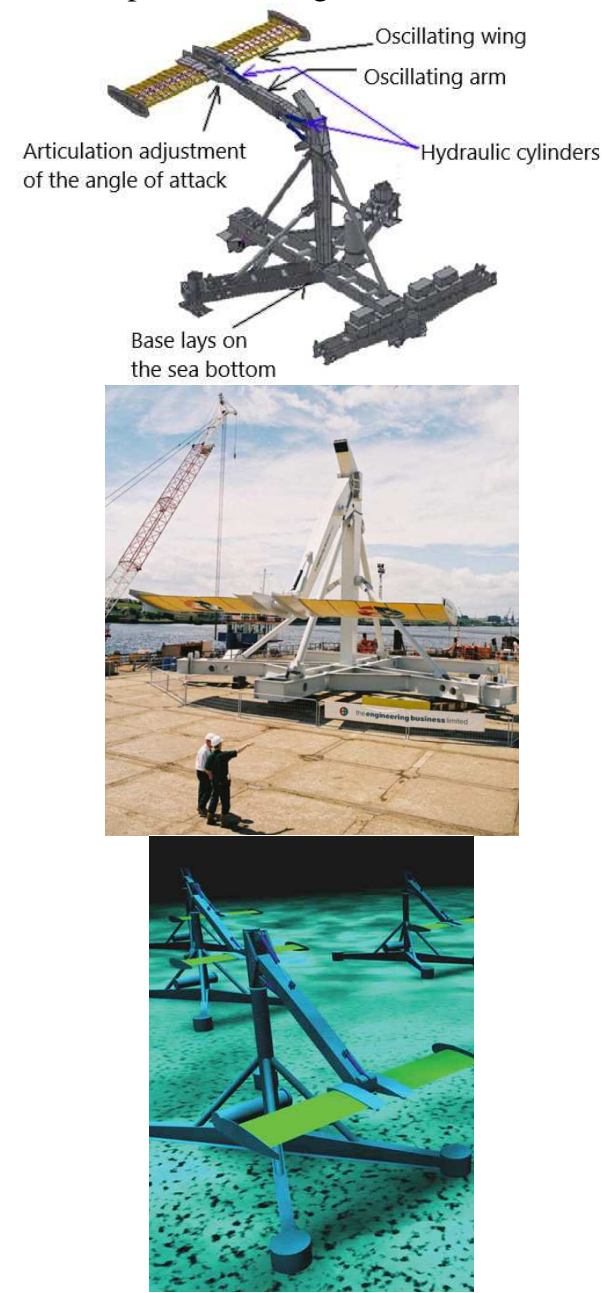

Fig.9. Stingray system with hydrofoil wing: drawing, photograph of the prototype and view of an underwater farm 
The angle of attack of the blades needs to be optimized incontinuously (hydraulic control) during vertical oscillations to maximize recovery. The set is designed to be laid and anchored at the bottom of the sea. A prototype $150 \mathrm{~kW}$ single wing (actually two half-wings aligned) was built, it occupies a floor area of $280 \mathrm{~m}^{2}$ and weighs 35 tonnes (185 tonnes including ballast). The halfwings are $7 \mathrm{~m}$ long and $3 \mathrm{~m}$ long and offer a total support surface of $42 \mathrm{~m}^{2}$. The support arm, $11 \mathrm{~m}$ long, allows oscillations of $+/-50^{\circ}$ or a vertical deflection of about $17 \mathrm{~m}$ and a catch section facing the current of $235 \mathrm{~m}$. The control of the movements requires a fine optimization of the function of evolution of the angles, in particular of the period. In a current of $2 \mathrm{~m} / \mathrm{s}$, a cycle period of $24 \mathrm{~s}$ leads to a power of $117 \mathrm{~kW}$. The system has been tested and a $500 \mathrm{~kW}$ version with 3 superimposed wings is planned.

\section{CONCLUDING REMARKS}

The projects of the tidal development are characterized by very large investments, long periods of construction and long periods of recovery of the investment.

Feasibility studies related to the installation of tidal power plants have estimated a considerable reduction in future energy production costs, due to new technological solutions for converting tidal energy. Assuming that it will be possible to exploit tidal currents with speeds over $3.5 \mathrm{~m} / \mathrm{s}$ and that the development of this technology continues, it is estimated that in the future, in practice, it will be possible to achieve low costs for obtaining electricity from tidal energy.

Tidal energy has several advantages:

- Hydropower is a renewable green energy. Its operation emits a very small amount of gaseous pollutants;

- The dam is used to channel the water level in the estuary during periods of high flood;
- The tidal coefficient is known several years in advance, allowing technicians to optimize the daily productivity of turbines.

Tidal energy has also some disadvantages:

- The ecological impacts are sometimes disastrous, the presence of the dam can upset the ecosystem of the estuary where it is located;

- Its implementation requires investments as well as significant operating costs;

- Electricity generation is not homogenous all year round, as it depends on the level of the tide.

The energy of the tides represents an important source of renewable energy that has been expanding in the last years and which is expected to progress rapidly since a lot of development projects had reached their maturity.

\section{REFERENCES}

[1]. Banal, M. "L'énergie marémotrice", REE $\mathrm{n}^{\circ} 8,1997$.

[2]. Bedard, R. et al., "Survey and characterization tidal in stream energy conversion (TISEC) devices", EPRI report TP-004 NA, 2005.

[3]. Black \& Veatch for Carbon Trust, " $U K$ Tidal Stream Energy Resource Assessment" - phase 2. Isleworth, United Kingdom: Carbon Trust, 2005.

[4]. Daviau, J.F. et al., "Divers aspects de l'exploitation de l'énergie des courants marins", Seatech Week Conf. Brest, 2004.

[5]. IRENA -International Renewable Energy Agency, "Ocean Energy: Technologie Readiness, Patents, Deployment Status and Outlook", 2014.

[6]. Multon, B. et al., "Systèmes de conversion des ressources énergétiques marines", Les Nouvelles Technologies de 1' Energie, Hermès Publishing, ISBN 2-7462-1376-1, 2006.

[7]. Pelc, R., Fujita, R., "Renewable energy from the ocean", Marine Policy Revue (Elsevier) $n^{\circ} 26,2002$.

Paper received on November $10^{\text {th }}, 2019$ 